IGCS20_1043

\section{ACTIVITY OF CHEMOTHERAPY IN RECURRENT UTERINE SEROUS CARCINOMA}

R Beavers*, B Fellman, M Eyada, A Klopp, N Fleming, K Lu, P Soliman, S Westin. University of Texas MD Anderson Cancer Center, USA

10.1136/ijgc-2020-IGCS.75

Background Uterine serous carcinoma (USC) carries a poor prognosis and the majority of patients develop recurrence. The study objective was to compare efficacy of chemotherapy regimens in recurrent USC.

Methods A retrospective review of patients with USC treated at our institution from 1993 to 2012 was performed. Recurrence-free survival (RFS) was estimated using methods of Kaplan and Meier and modeled via Cox proportional hazards regression. RFS1 was calculated from date of first recurrence to second recurrence. Platinum-sensitivity was defined as recurrence $>6$ months after platinum-based therapy. Those never exposed to chemotherapy during adjuvant therapy were included in the platinum-sensitive cohort.

Results Of 313 patients, 147 (47\%) had recurrence. Median age was 64 years; $65 \%$ were stage III/IV. Median follow up was 39.3 months. Median RFS1 was 5.5 months (95\% CI 0.7 - 31.4). 115 patients (78\%) received chemotherapy alone. Objective response was highest in the platinum-sensitive compared with the platinum-resistant cohort $((21 / 84 ; 25 \%)$ vs. (4/ $35 ; 11 \%))$. In platinum-sensitive disease treated with chemotherapy, platinum-based had higher response compared to non-platinum-based regimens $(18 / 44(41 \%)$ vs $3 / 41(7 \%)$ $\mathrm{p}=0.029)$. Response in platinum-resistant tumors to platinumbased regimens was $37 \%(3 / 8) .86 \%$ of patients with platinumresistance had progressive disease regardless of chemotherapy. 86 patients $(27 \%)$ had a second recurrence, $47(55 \%)$ were platinum-sensitive and $36(77 \%)$ were treated with chemotherapy. Response to chemotherapy was $5 \%$ in those with a second recurrence.

Conclusion In patients with recurrent USC deemed platinumsensitive at first recurrence, platinum-based regimens may be associated with improved response. Platinum-resistant tumors do not appear to have an optimal second-line chemotherapy regimen.

\section{IGCS20 1045}

\section{A STUDY ON THE KNOWLEDGE AND AWARENESS OF CERVICAL CANCER AMONG COLLEGE STUDENTS AND ASSESSING THE IMPACT OF TRAINING SESSIONS ON CERVICAL CANCER AWARENESS}

A Rajanbabu*, V Patel. Anupama Rajanbabu, India

\subsection{6/ijgc-2020-IGCS.76}

Background Cervical cancer is a major public health problem in India. In India there is a need for an intensive and sustained effort from health workers to improve awareness in order to increase prevention and screening. This study is an attempt to assess the knowledge of college students from various institutions about cervical cancer and to evaluate the impact of a cervical cancer awareness program on their knowledge.

Material and Methods Multiple training sessions on cervical cancer awareness was conducted in January and February 2020 at various colleges around Kochi, Kerala, India. A pre and post awareness session questionnaires were administered which included fifteen questions covering various aspects of cervical cancer screening and prevention.

Results The study was conducted in five different colleges across the district. Total of 485 students attended the awareness sessions and 449 were willing to participate in the study. Out of these students 160 were Para medical students and 289 non medical students. Knowledge about cervical cancer, methods of screening and prevention, benefits of vaccination were all low before which significantly improved post awareness session. The paramedical students performed significantly well than non medical students in the pre test but the post test scores showed the knowledge levels were similar in both the groups with the non medical students even outperforming paramedical students in certain areas.

Conclusions The awareness sessions improved the knowledge about cervical cancer and methods for prevention in both medical and non medical students. After the awareness session, majority of the students felt more knowledgeable and safe.

\section{IGCS20 1046}

\section{UNUSUAL EXTRAUTERINE LOCALISATION OF LOW GRADE ENDOMETRIAL STROMAL SARCOMA : REPORT OF TWO CASES}

${ }^{1} \mathrm{M}$ Slimene*, ${ }^{1}$ I Bouraoui, ${ }^{1} \mathrm{M}$ Bouhani, ${ }^{1} \mathrm{~S}$ Sakhri, ${ }^{2} \mathrm{~N}$ Boujelbene, ${ }^{1} \mathrm{R}$ Chargui, ${ }^{1} \mathrm{~K}$ Rahal ${ }^{1}$ Department of Surgical Oncology, Salah Azaiez Institute, Tunisia; ${ }^{2}$ Department of anatomopathology, Salah Azaiez Institute, Tunisia

\subsection{6/ijgc-2020-IGCS.77}

Introduction Endometrial stromal sarcoma (ESS) is an uncommon malignant mesenchymal tumor. Uterine localization is frequently seen but low grade ESS arising in extrauterine sites is so rare. Clinical presentation of this entity is no specific. So that, the diagnosis is based on histological analysis.

Methods We report two cases of low garde extrauterine endometrial stromal sarcoma treated at Salah Azaiez Institute.

Results The first case was a premenopausal female presented with abdominal pain. MRI examination showed an abominopelvic mass. She had right salpingooophorectomy. Microscopic analysis showed a low graden endometrial stromal sarcoma probably arising from endometriosis. Six months after, CT scan revealed pelvic recurrence depending on the ovary. She had hysterectomy with left salpingooophorectomy, omentectomy and appendicectomy. Histological report concluded on low graden ESS of ovary arising from endometriosis. The second case was a postmenopausal women with the history of hysterectomy with bilateral salpingoophorectomie for benign fibroma presented with pelvic pain. CT scan showed two abdominal mass. Peroperatory, there were three mass depending on the mesorectum, the mesentery and the epiplon. Dissection was difficult. Epiploic biospy was taken. After histological and immunohistochemical study, the diagnosis of low grade extrauterine endometrial stromal sarcoma was retained. Hormonal therapy with regular follow up were indicated. 